\title{
DEVELOPMENT AND PRELIMINARY EVALUATION OF PCM THERMAL ENERGY STORAGE FOR AIR COOLING IN BUILDINGS
}

\author{
P. PONTELANDOLFO ${ }^{1}$, P. HAAS ${ }^{1}$, R. DA SILVA LIMA ${ }^{1}$, R. PUTZU ${ }^{1}$, O. SARI $^{2} \&$ P. NIKKOLA ${ }^{2}$ \\ ${ }^{1}$ University of Applied Sciences and Arts Western Switzerland, HEPIA-Genève, Switzerland. \\ ${ }^{2}$ University of Applied Sciences and Arts Western Switzerland, HEIG-VD, Switzerland.
}

\begin{abstract}
This study presents the development of a real-scale latent heat thermal energy storage (TES) device based on an air-PCM (phase change material) heat exchanger. The device uses the outdoor ambient temperature difference between night and day to refresh the indoor air and shift or completely avoid the use of air-conditioning in air-cooling in the building sector. The design is based on an extensive set of numerical simulations, performed by the commercial software ANSYS Fluent, focused on a parametric study allowing to identify the optimum value of different design parameters in order to have 10 hours of temperature shift. The numerical simulations were supported by experimental measurements done with a small-scale test rig. Additionally, the thermal response of the PCM to cooling and heating was also studied in a controlled temperature and humidity environment.

Keywords: Buildings, CFD Simulations, Phase change material (PCM), Prototype development and realization, Thermal energy storage
\end{abstract}

\section{INTRODUCTION}

The energy demand due to air-conditioning in buildings is a big issue for the electrical distribution in a city [1]. The reduction of the energy consumption and the improvement of the existing methods to store energy are crucial nowadays. The use of TES device to refresh the indoor air of a building can decrease the use of air-conditioning and, generally, enhance the energy efficiency of buildings [2].

TES for building cooling have been classified as active or passive [3]. The use of active TES gives a high control on the indoor conditions. This kind of system contains mechanically assisted components which create interactions between the system and the energy source. On the other hand, in a fully passive TES the thermal exchange between system and source is provided only by natural phenomena without any external device. Passive TES systems maintain the comfort conditions in buildings and minimize the use of mechanically assisted heating or cooling systems. The present work is the design of a passive thermal storage device with a minimal use of external devices.

It is well know that it can be possible to create a temperature shift between entry and exit of a passive TES [4-7]. In normal conditions, the temperature during the day changes from a minimal value, which is normally measured during the night, to a maximal value, which is normally measured during the day, and they are shifted of around 12 hours. M. Zgraggen and Dr. P. Hollmuller showed that the cold peak can be delayed of different hours and used as refreshing renewable air source during the day $[8,9]$.

The use of PCM in TES is an effective efficient way of storing thermal energy [10]. In PCMs, latent heat storage can be used to store more efficiently thermal energy if the phase transition temperature is located inside the operational temperature condition. PCMs can be a very attractive method in large number of applications and, based on the phase change process, they can be classified into solid-liquid, liquid-gas and solid-solid PCM [11, 12]. With 
regard to the presented prototype, the chosen PCM material contains specially developed PCM microcapsules which change phase within humans' comfort zone at around $23^{\circ} \mathrm{C}$.

The principle of PCM use is very simple, but evaluating the effective contribution of the latent heat loads in the enhancement of the energy performance of the system is more complex. Therefore, the thermal response of the chosen PCM was analyzed in a controlled temperature and humidity environment. The solid-liquid phase change can be investigated with numerical study or simulations. Commercial and open source software are used to solve fluid flow problems involving the solidification and/or melting process which takes place at one temperature (e.g. in pure metals) or over a range of temperatures (e.g. in binary alloys) [13]. In order to design and optimize the energy storage device, an extensive set of numerical simulations with the commercial software ANSYS Fluent was carried out in order to identify the optimum value of the different design parameters. The numerical simulations were validated by experimental measurements performed on a small-scale test rig.

Measurements on the prototype in terms of temperature time shift and a discussion on the design and develop the thermal storage prototype are here presented. The built prototype will be installed in an existing building in Sion and monitored in the next few months in order to collect more experimental data and verify the energy economy compared with traditional air-conditioning methods.

\section{PROPOSE AND PROTOTYPE TECHNICAL SPECIFICATIONS}

The prototype will be used to refresh a laboratory of the University of Applied Sciences and Arts Western Switzerland in Sion $(\mathrm{CH})$. The room dimensions are $10.3 \mathrm{~m} \times 8.7 \mathrm{~m} \times 2.9 \mathrm{~m}$ and maximal number of people who work inside the room is 10 .

Based on the specifications of the building, its use and meteorological data, the heating and cooling requirements of the building where modelled and simulated. The data obtained from those simulations allowed to set design requirements-energy storage-of the system.

\section{BUILDING MODEL AND SIMULATION}

The building was modelled based on the technical specifications of its thermal envelope, its use and the local meteorological data (solar radiation and air temperature). For comparison purposes, two models were developed, static and dynamic. Both models were obtained from an energy balance. The dynamic model was developed using an $R 2 C$ electrical equivalent approach ( 1 resistance and 2 condensers).

Each model resulted in a series of equations that were set in a matrix and solved numerically. A simple application was developed to allow navigating in a dynamic time-window of the results. The results showed that the cooling power requirements obtained with the static and dynamic model are significantly different. That is due to the effect of the inertia of the building. Based on the results obtained with the dynamic model, the cooling power requirements were set to $5 \mathrm{~kW}$.

\section{PROTOTYPE COMPONENTS AND DESIGN}

As already mentioned in the introduction, the main propose of the TES device is to create a temperature peak swift between entry and exit using the PCM materials. The main components of the TES prototype are three: a mechanical fan, the adiabatic box and the PCM material, see Fig. 1. The TES design was divided into four phases.

In the first phase, the PCM material was chosen. The construction material contains developed PCM microcapsules which change phase within humans' comfort zone at $23^{\circ} \mathrm{C}$. 


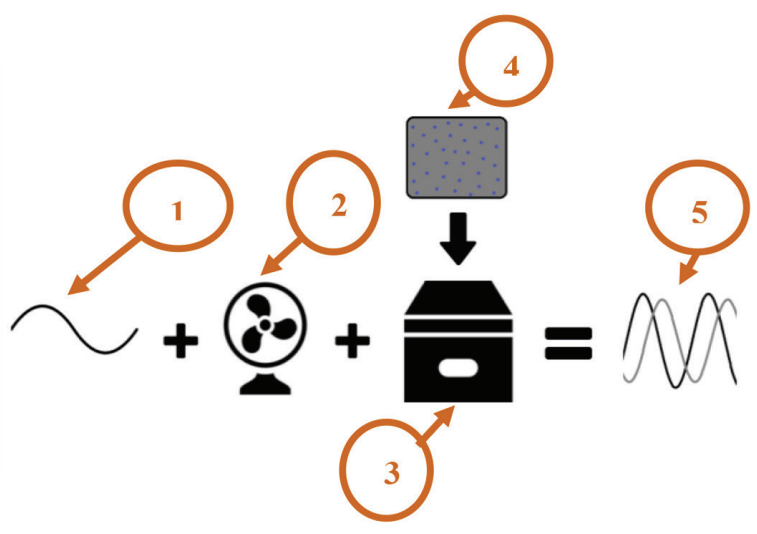

1. Daily temperature variation: outdoor

2. Mechanical fan

3. Adiabatic box

4. PCM material

5. Temperature variations: outdoor (entry) and exit from the TES prototype

Figure 1: Basic schema with the components of the TES prototype.

The proprieties of the chosen PCM are: phase transition temperature at $23^{\circ} \mathrm{C} \pm 1{ }^{\circ} \mathrm{C}$, latent heat of $291 \mathrm{~kJ} / \mathrm{m}^{2}$, PCMs are flat rectangular plate of $0.5 \mathrm{~m} \times 1 \mathrm{~m} \times 25 \mathrm{~mm}$. The chosen material was selected for the following principal reasons: the outdoor ambient temperatures during the summer in Switzerland often exceed $23^{\circ} \mathrm{C}$ (measures of the temperature in Sion available on internet website: 'http://www.prevision-meteo.ch/climat/annuel/sion', flat rectangular plates are easy to manage and they can be piled leaving a fixed space between them.

In the latter phase, the thermal exchange between the PCM plates is analyzed by CFD simulations. The results of this phase are described and analyzed in 6.1 and it gives as optimal plate distance $6 \mathrm{~mm}$. The optimal plate distance with the total air mass flow and plate width of $1,000 \mathrm{~mm}$ give as plates' number to be piled of 15 .

In the third phase, the TES device's length was estimated by a second CFD simulation campaign. The results of this phase are described and analyzed in the Paragraph 6.2. In order to have around 10 hours of temperature shift, the TES device's length was evaluated equal to $3 \mathrm{~m}$.

The fan performance characteristic was defined considering a security coefficient of 2 on the pressure drop calculated with the simulation in the previous phase.

\section{THERMAL RESPONSE OF THE PCM}

In order to observe and understand the thermal response of the product used for the construction of the prototype (AlbaBalance), samples were tested inside a thermal and humidity controlled oven. A total of four samples were tested, each with $300 \mathrm{~mm} \times 300 \mathrm{~mm} \times 25 \mathrm{~mm}$, two with a phase-change temperature of $23^{\circ} \mathrm{C}$ and the remaining two with a phase-change temperature of $26^{\circ} \mathrm{C}$.

Each sample was equipped with two-type $\mathrm{K}$ thermocouples (2-mm diameter), one placed on the top surface and the other inserted in a 2-mm diameter hole on the side of the sample ( $25 \mathrm{~mm}$ thick, thus at $12.5 \mathrm{~mm}$ from the top surface). Figure 2 depicts the samples positions inside the oven. As can be seen, samples were positioned at different height levels. For that reason, two thermocouples-one at each level-were used to measure the ambient temperature inside the oven. Table 1 gives the details of the phase-change temperature and position of each sample. 


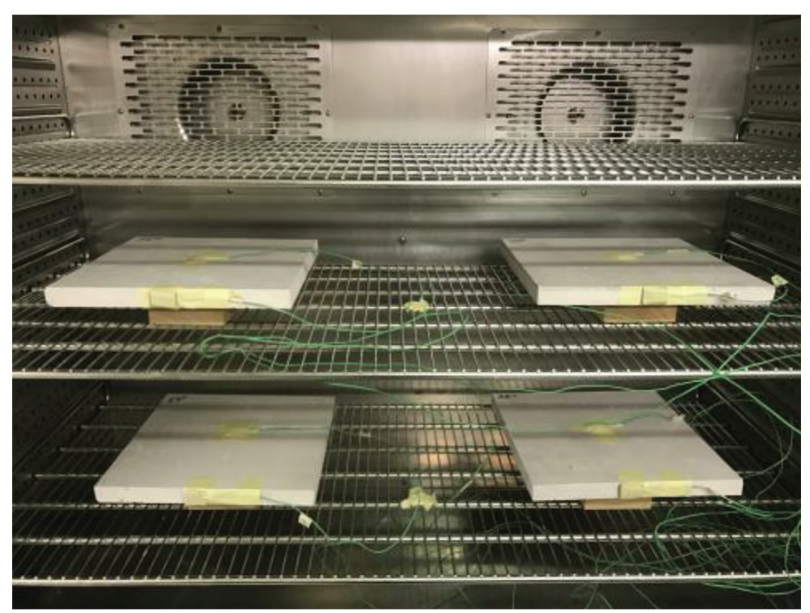

Figure 2: AlbaBalance samples placed in the oven.

Table 1: Phase change temperature and position in the oven of the samples.

\begin{tabular}{lll}
\hline Sample & Phase-change material $\left({ }^{\circ} \mathrm{C}\right)$ & Position \\
\hline 1 & 23 & Top-right \\
2 & 26 & Top-left \\
3 & 26 & Bottom-right \\
4 & 23 & Bottom-left \\
\hline
\end{tabular}

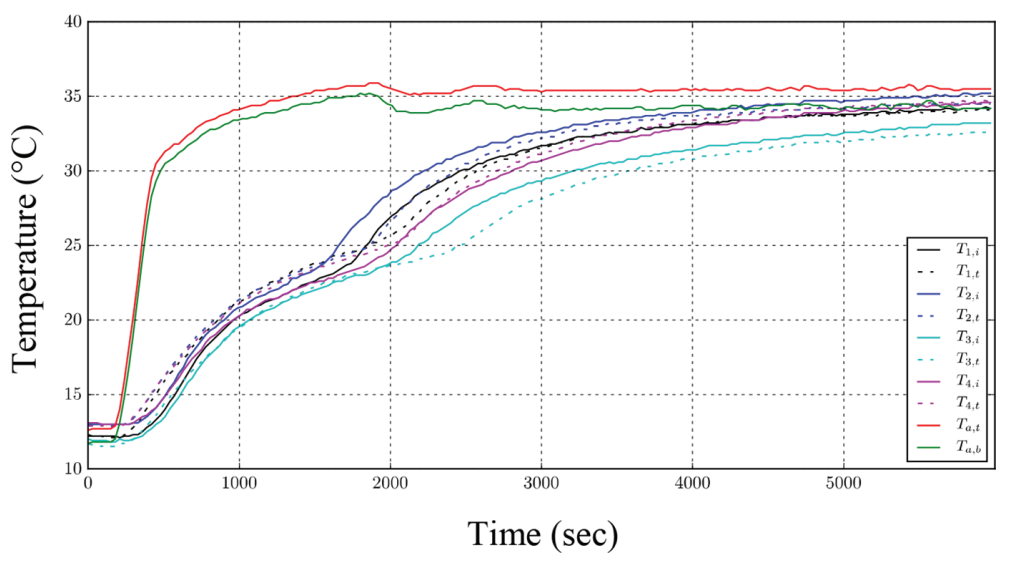

Figure 3: Thermal response during heating cycle. $T_{x, y}$ refers to the sample temperature measurement, where $x$ is an integer and stands for the sample number and $y$ is a letter $i$ or $t$ and stands for internal or top measurement. $\mathrm{T}_{\mathrm{a}, \mathrm{x}}$ refers to the ambient air temperature measurement in the oven, where $\mathrm{x}$ is a letter $t$ or $b$ and stands for top or bottom measurement. 
The measurements were made for two cycles of heating and cooling between 13 and $35^{\circ} \mathrm{C}$ at constant relative humidity of $35 \%$. The results have shown that at steady state, the temperature difference between all the measurements (including air temperature) was systematically below $\pm 1^{\circ} \mathrm{C}$ in regards of the average value, which is very good. Both heating and cooling cycles depicted similar results and trends. The temperature measurements (top and internal) have depicted slope variations during heating and cooling phases. The slope variations result from the phase-change process occurring within the samples. Figure 2 depicts the thermal response during the heating cycle. During phase-change the value of the slope of the temperature decreases but is not 0 . The change of slope value does not occur exactly at the predefined temperature (i.e. $23^{\circ} \mathrm{C}$ or $26^{\circ} \mathrm{C}$ ). It was impossible to distinguish $23^{\circ} \mathrm{C}$ from $26^{\circ} \mathrm{C}$ phase-change samples. The analysis of the thermal response results indicates that the amount of PCM and the volumetric homogeneity of the mixture are important parameters that can be optimized.

\section{CFD SIMULATIONS AND VALIDATION BY EXPERIMENTAL MEASUREMENTS WITH A SMALL-SCALE TEST RIG}

In order to design the TES prototype, different CFD simulations were carried out. The commercial software ANSYS Fluent was used to solve the fluid dynamics equations.

The heat exchange between the PCM material and air is solved solving the basic fluid mechanics equations. The investigations are performed assuming air behaving as an uncompressible gas. The effects of the turbulence are implemented using the $k-\varepsilon$ realizable RANS model that is already implemented in commercial software. A SIMPLE (Semi-Implicit Methods for Pressure Linked Equations) is used for the pressure calculation.

Melting of the PCM is governed by the unsteady Navier-Stokes equations in the form of equations for continuity, momentum, and energy. The code solves phase-transition problems through the enthalpy porosity method which assumes a linear enthalpy-temperature relationship and ignores enthalpy hysteresis. The liquid-solid mushy zone is treated as pseudo-porous zone where the liquid fraction $\beta$ lies between 0 (solid) and 1 (liquid). The liquid fraction $\beta$ of $\mathrm{PCM}$ is calculated with the eqn. 1 below [16]:

$$
\beta=\left\{\begin{array}{c}
0, T<T_{\text {Solidus }} \\
\frac{T-T_{\text {Solidus }}}{T_{\text {Liquidus }}-T_{\text {Solidus }}}, T_{\text {Solidus }}<T<T_{\text {Liquidus }} . \\
1, T \geq T_{\text {Liquidus }}
\end{array}\right.
$$

Source terms in both momentum and thermal equations in ANSYS Fluent are introduced and they are function of $\beta$. The enthalpy calculation is expressed as function of the latent heat of the PCM material and $\beta$.

Due to the PCM shapes and to have a high mesh quality, hexahedral elements were used for all simulations (rectangular elements in 2-dimension simulation).

In order to validate the model, a small-scale test rig was developed and instrumented with temperature sensors ( $\mathrm{K}$ thermocouples), see Fig. 4. Data was collected by appropriate National Instruments sensor node (NI-cDAQ-9188XT) that communicates with host computer that received, processed, controlled the heating resistances, stored and displayed the collected information via LabVIEW environment. The daily temperature profile was created by an electric heating resistance controlled by LabVIEW program. The PCM plates were installed in a thermal isolated enclosure of $1500 \mathrm{~mm} \times 800 \mathrm{~mm} \times 500 \mathrm{~mm}$. Both air velocity and plates' distance between plates was kept constant during the test. 


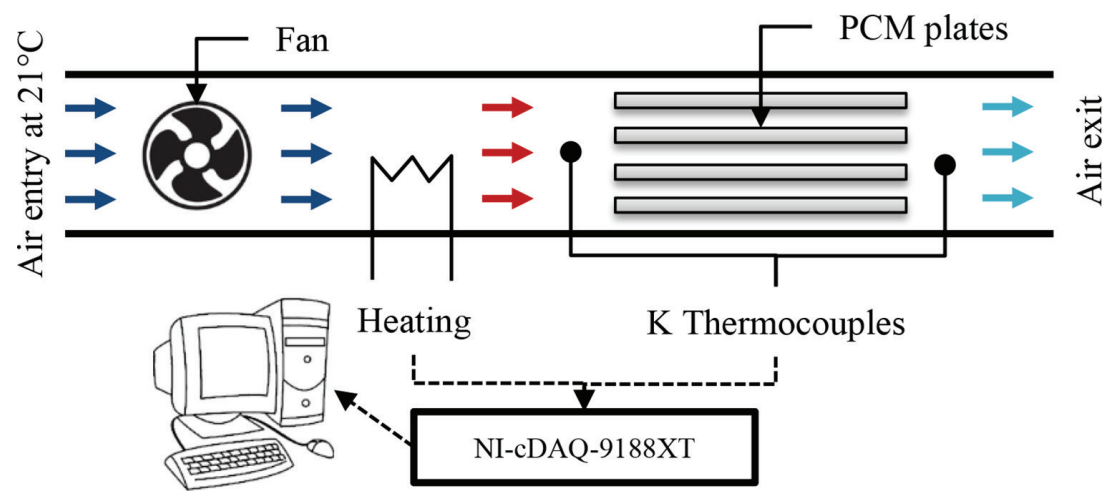

Figure 4: Experimental setup for the small-scale test rig.

Temperature measurements were used to evaluate both Temperature Peak Shift (TPS) between the entry and the exit of the test rig and Temperature Amplitude Damper (TAD) and calculated as the eqns (2) and (3) (see Fig. 5):

$$
\begin{gathered}
\text { Temp. pickshift }(h)=\operatorname{TPS}(h)=\frac{\left(\text { Time }\left.\right|_{B}-\text { Time }\left.\right|_{A}\right)+\left(\text { Time }\left.\right|_{D}-\text { Time }_{C}\right)}{2} \\
\text { Temp.ampliture damper }(\%)=\operatorname{TAD}(\%)=\frac{\left(\text { Time }\left.\right|_{B}-\text { Time }_{D}\right)}{\left(\text { Time }\left.\right|_{A}-\left.\operatorname{Time}\right|_{C}\right)} \cdot 100
\end{gathered}
$$

Figure 6 depicts the CFD results at different average speeds of the air between plates (continuous line and round mark) and the experimental data measured with the small-scale test rig (no line and square mark) in terms of TPS (blue colour) and TAD (red colour). Figure 6 shows a good agreement between numerical results and experimental data with an error of less than 15 minutes and $8 \%$ in terms of TPS and TAD, which validates the use of the simulation as a tool to investigate the PCM materials for the TES applications.

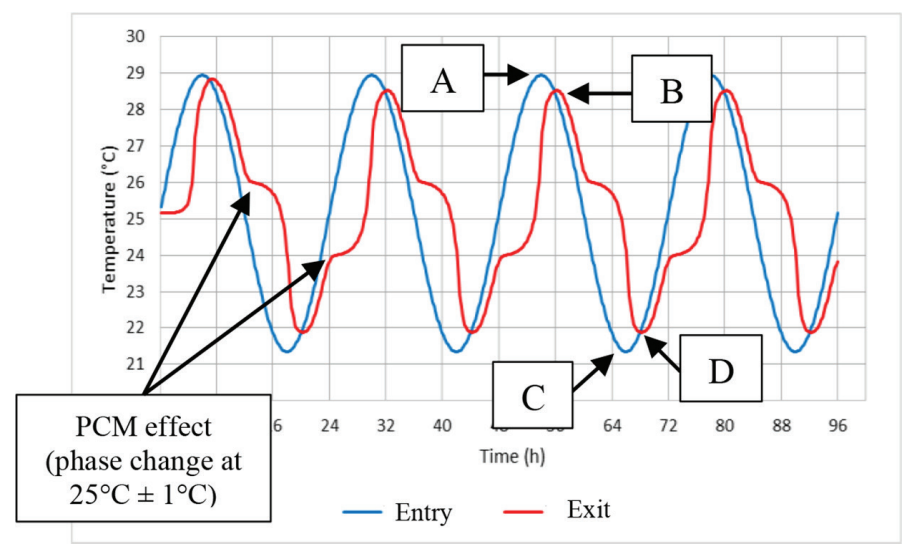

Figure 5: Example of a temperature profile at the entry and the exit of the TES. 


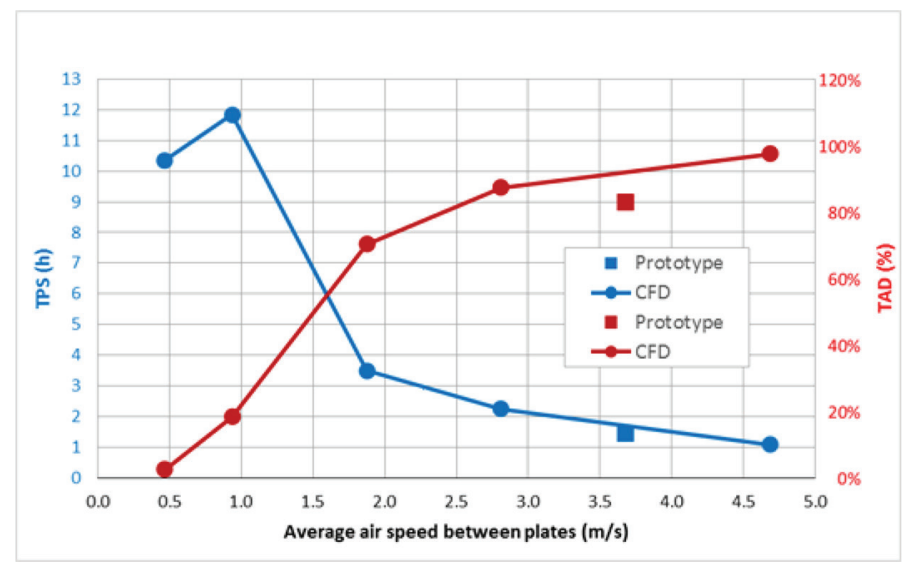

Figure 6: CFD results and experimental measurements in terms of TPS and TAD.

6.1 First CFD analysis: Investigation of the thermal exchange between each PCM plate

A first CFD analysis was carried out to investigate the thermal exchange between each PCM plate. The average air speed between plates and plate distances were analyzed.

Figure 7 depicts the CFD results of the plates distance analysis. All the parameters in each simulation (boundary conditions, entry temperature profile, mesh...) are similar. Figure 7 shows that, up to $6 \mathrm{~mm}$ of plates distance and for average air speeds larger than $0.25 \mathrm{~m} / \mathrm{s}$, TPS and TAD are similar for the same average air speed.

Figure 8 depicts the CFD results of the plates distance analysis keeping the same entry mass air flow. Figure 8 shows that, up to $6 \mathrm{~mm}$ of plates distance and for average air speeds larger than $0.25 \mathrm{~m} / \mathrm{s}$, TPS is constant and TAD slightly decreases for the same entry mass air flow. This was the main reason we choose $6 \mathrm{~mm}$ as the optimal value: for the same entry mass air flow, the TPS is high and the TAD is as higher as possible.

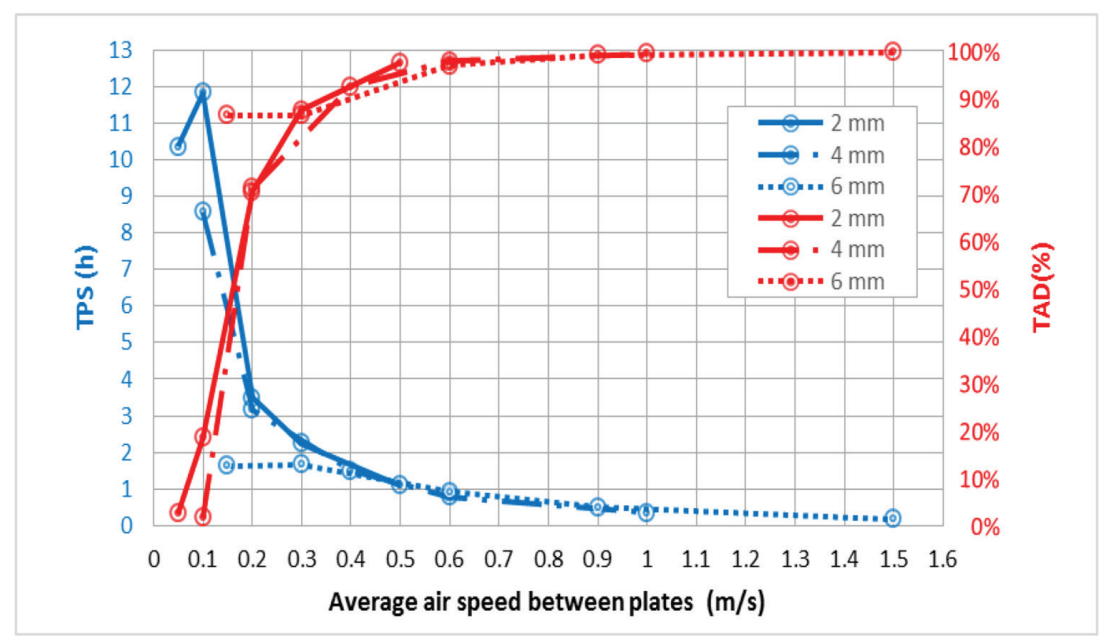

Figure 7: Plates distance analysis in terms of TPS (h) and TAD (\%) at different average air speed between PCM plates. 


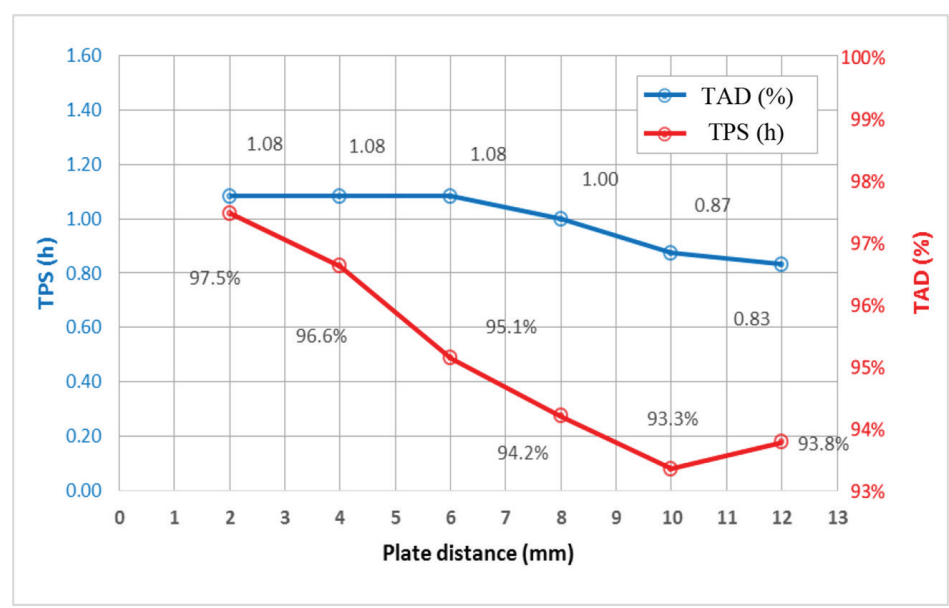

Figure 8: Plates distance analysis in terms of TPS (h) and TAD (\%) for the same entry mass air flow.

\subsection{Second CFD analysis: Assessment of the length of the TES prototype}

A second CFD analysis was carried out to assess the length of the TES prototype. Except for the plates' length, all the parameters in each simulation (boundary conditions, entry temperature profile, mesh...) are similar to the ones of the First CFD analysis. Figure 9 shows that, with a plate distance of $6 \mathrm{~mm}$ and total air mass flow of $300 \mathrm{~m}^{3} / \mathrm{h}, 3$ meters of TES prototype length allow achieving around 10 hours of TPS (green line).

\subsection{D effects: A CFD analysis}

In the real application, the upper and lower plates can be easily posed on isolated walls. Unfortunately, the external plates do not exactly work as the middle PCM plates and this unwanted effect, here called 3D effect, can decrease the system efficiency.

In order to evaluate this 3D effect, a CFD simulation was carried out where the external plates have exactly half height $h$ of a standard plate $(h=25 \mathrm{~mm} / 2=12.5 \mathrm{~mm})$. The results of

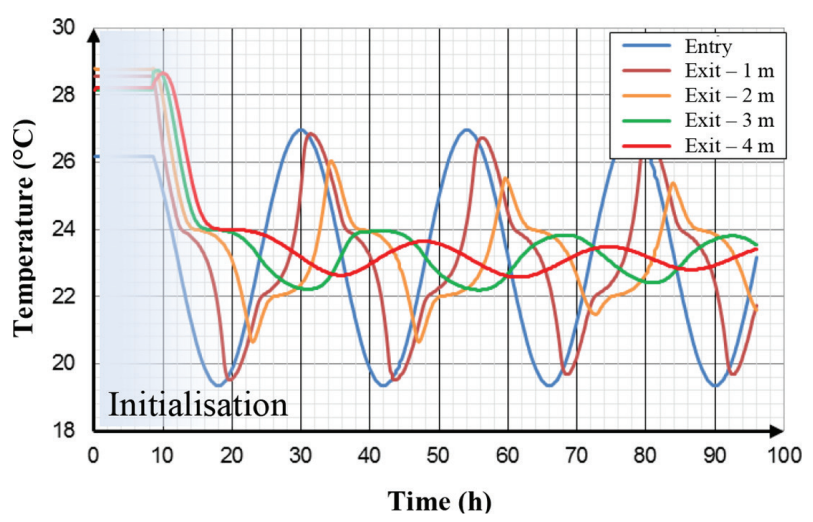

Figure 9: CFD results to assess of the length of the thermal storage device. 
the simulation give the following results: the TPS does not change, instead the TAD increases of around $9 \%$.

Even if the thermal gain we have when the half PCM plate solution is considered, both the scarce gain in terms of TAD and the difficulty to cut the plate forced us to keep the solution with the normal plates as external elements.

\section{TES PROTOTYPE AND PRELIMINARY MEASUREMENTS}

As explained in the previous paragraphs, the TES prototype design was performed by simulations and the main characteristics are here summarized:

- PCM material: flat rectangular plates of $0.5 \mathrm{~m} \times 1 \mathrm{~m} \times 25 \mathrm{~mm}$ with phase transition temperature at $23^{\circ} \mathrm{C} \pm 1{ }^{\circ} \mathrm{C}$.

- Air mass flow of $300 \mathrm{~m}^{3} / \mathrm{h}$.

- PCM stock characteristics:

O Dimensions: $\sim 0.5 \mathrm{~m} \times 1 \mathrm{~m} \times 3 \mathrm{~m}$.

O Number of plates: 15 .

○ Plate distance: $6 \mathrm{~mm}$.

Similar to small-scale test rig, TES prototype was developed and instrumented with different temperature sensors ( $\mathrm{K}$ thermocouples), data was collected by appropriate National Instruments sensor node (NI-cDAQ-9188XT) and displayed via LabVIEW environment, see Fig. 10.

As described in the introduction, TES prototype will refresh the indoor air during the day to avoid the use of air-conditioning. To accomplish the mission, TES prototype has two separate air exits in order to blow the air either inside the building (during the day) or outside (during the night). The exits can be controlled by electronic actuators commanded by an analogic signal.

Figure 11 depicts the air temperature measurements before the PCM plates with blue line and after the PCM plates with red line. The TES prototype creates 10 hours of TPS with a TAD of around $27 \%$, during summer days when the air temperature ranges from around $15^{\circ} \mathrm{C}$ to $27^{\circ} \mathrm{C}$. The 10 hours TES forecast with the simulation is achieved.
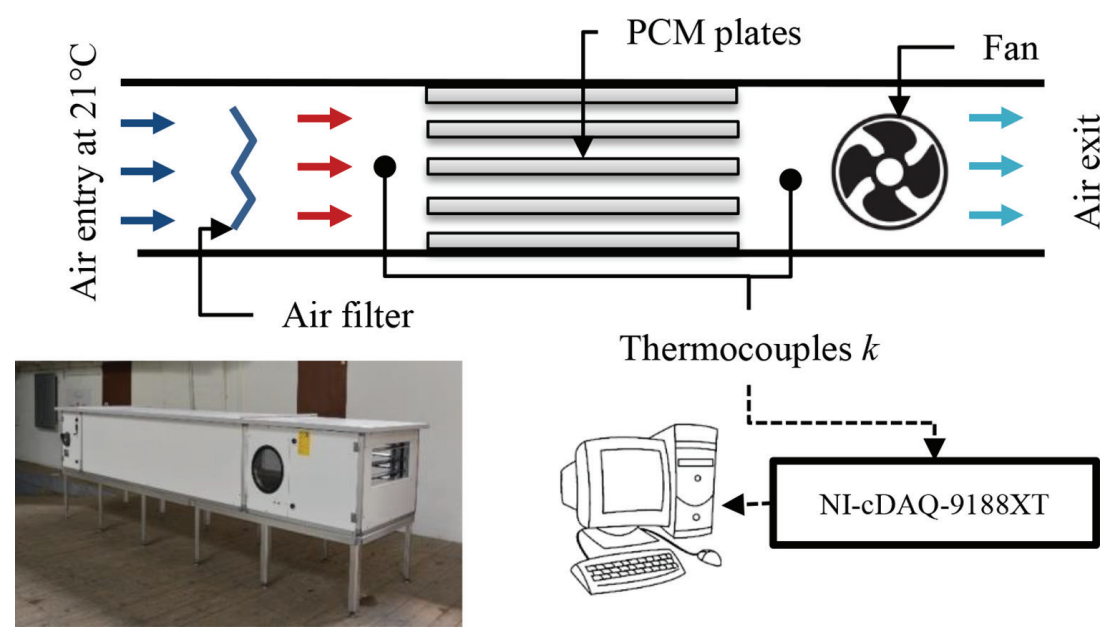

Thermocouples $k$

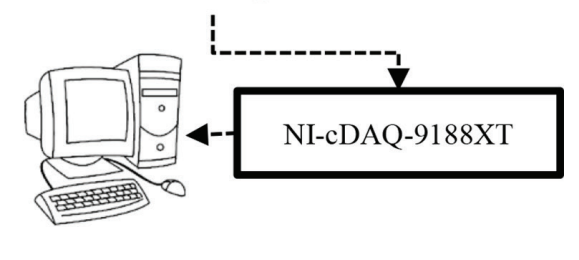

Figure 10: TES prototype (scheme of the apparatus with photo). 


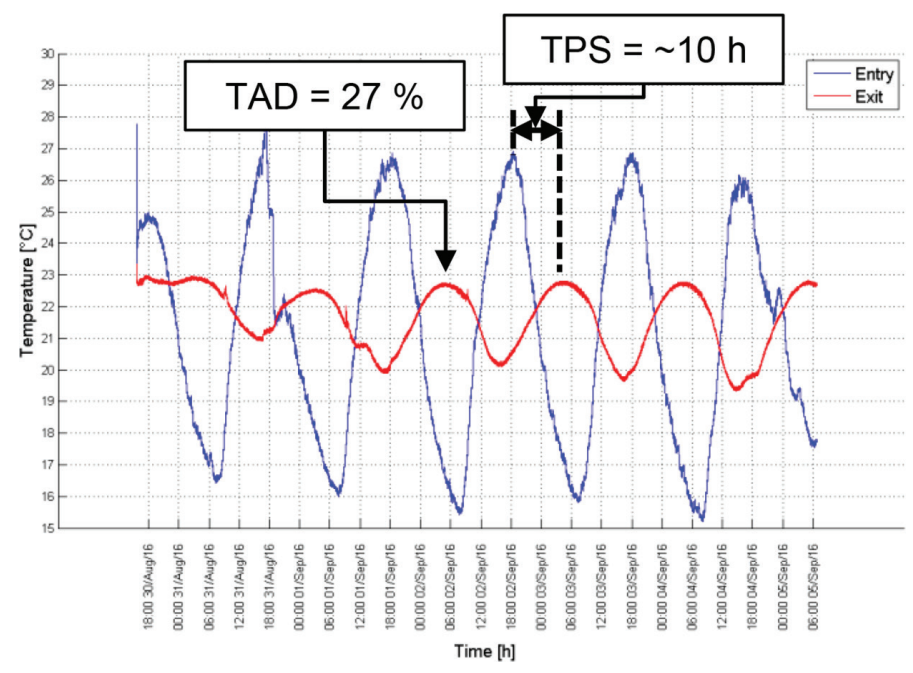

Figure 11: Air temperature at the entry in blue line, or before the PCM plates, and at the exit in red line, or after the PCM plates.

Table 2: TPS and TAD for different air mass flows.

\begin{tabular}{llll}
\hline & \multicolumn{2}{l}{ Mass air flow $\left(\mathrm{m}^{3} / \mathrm{h}\right)$} & \\
\cline { 2 - 4 } Parameter & Subheading & Subheading & Subheading \\
\hline TPS $(\mathrm{h})$ & 10 & 6 & 3 \\
TAD $(\%)$ & 27 & 57 & 80 \\
\hline
\end{tabular}

Further experimental measurements were carried out with a mass flow of $600 \mathrm{~m}^{3} / \mathrm{h}$ and $1,200 \mathrm{~m}^{3} / \mathrm{h}$ in order to evaluate the TES performances at different regimes. The results in terms of TPS and TAD are shown in Table 2. Results show that the higher is the air mass flow, the higher is the TPS and the lower is TAD.

\section{CONCLUSIONS AND PROSPECTIVE OF THE PROJECT}

University of Applied Sciences and Arts Western Switzerland initiated a long-term research project in order to design and test a real-scale latent heat TES device based on an air-PCM heat exchanger for use as air-cooling in the building sector. The TES was design to refresh a laboratory in Sion and based on the specification of the building and local meteorological conditions a model was developed. Static and dynamic simulations were made. The resulting cooling needs were used to set design requirements-energy storage-of the system.

Experimental tests were conducted to study the thermal response of the phase-change material used in the prototype. Results were similar for heating and cooling cycles. The thermal response showed the effect of the phase-change phenomena. The analysis of the thermal response results indicates that the amount of PCM and the volumetric homogeneity of the mixture are important parameters that can be optimized.

The design procedure was based on an extensive set of CFD simulations which allowed to determine the TES characteristics. The simulations were performed by the commercial software ANSYS Fluent and validated by an experimental small-scale test rig. 
Different experimental measurements were carried out to verify the foreseen TPS of 10 hours and to analyze the dynamic behaviour of the TES. Further experimental campaigns were carried out in order to investigate the TPS and the TAD for air mass flow of $600 \mathrm{~m}^{3} / \mathrm{h}$ and $1,200 \mathrm{~m}^{3} / \mathrm{h}$.

The TES prototype will be installed in Sion in Switzerland and monitored in the next few months in order to collect more experimental data and verify the energy economy compared with traditional air-conditioning methods.

\section{ACKNOWLEDGMENTS}

The present was supported by the University of Applied Sciences and Arts Western Switzerland-HES-SO.

The authors acknowledge Blerim Arslani for his valuable contribution to complete and analyze many of CFD simulations.

\section{REFERENCES}

[1] Santamouris, M., Air-conditioning: energy consumption and environment quality, Encyclopedia of Life Support System (EOLSS), 2009.

[2] Pérez-Lombard, L., Ortiz, J. \& Pout, C., A review on buildings energy consumption information. Energy and Buildings, 40(3), pp. 394-398, 2008.

https://doi.org/10.1016/j.enbuild.2007.03.007

[3] Gil, A., Medrano, M., Martorell, I., Lázaro, A., Dolado, P., Zalba, B. \& Cabeza, L.F., State of the art on high temperature thermal energy storage for power generation. Part 1 - Concepts, materials and modellization. Renewable Sustainable Energy Reviews, 14, pp. 31-55, 2014. https://doi.org/10.1016/j.rser.2009.07.035

[4] Haas, P. \& Schmitt, P.L., Etude de l'aérodynamique interne d'un déphaseur d'ondes thermiques, Projet HES-SO, hepia-cmefe, 2009.

[5] Bernhard, M., Realizzazione e analisi di un prototipo per lo sfasamento dell'onda termica giornaliera estiva per il raffrescamento di ambienti residenziali, Master thesis at Bologna University, Prof. P. Haas (hepia-cmefe) and Prof. B. Pulvirenti (UNIBO), 2015.

[6] Egolf, P.W., Noume, A.N., Vuarnoz, D. \& Gottschalk, G., Breathing building: A decentralized façade-integrated solar air-conditioning system, UNEP 2014.

[7] Muriset, C., Egolf, P.W., Vuarnoz, D. \& Haas, P., Lowering and phase shifting of temperature profiles with phase change materials in Minergie houses, 8th IIR Conference on phase change materials and slurries for refrigerating and air conditioning, Karlsruhe, 2009.

[8] Zgraggen, J.-M., Etude d'un lit de sphères pour le déphasage d'une onde thermique Calcul analytique et vérification expérimentale, Student work of the Geneva University, 10 October 2003.

[9] Hollmuller, P., Lachal, B., Zgraggen, J.-M., Pampaloni, E., Mezzo J., Déphaseur thermique diffusif, Rapport for the Swiss Federal Office of Energy SFOE, June 2004.

[10] Sharma, A., Tyagi, V.V., Chen, C.R. \& Buddhi, D., Review on thermal energy storage with phase change materials and applications. Renewable and Sustainable Energy Reviews, 13, pp. 318-345, 2009.

https://doi.org/10.1016/j.rser.2007.10.005

[11] Abhat, A., Low temperature latent heat thermal energy storage: heat storage materials. Solar Energy, 30(4), pp. 313-332, 1983. https://doi.org/10.1016/0038-092x(83)90186-X 
[12] Kumar, A. \& Shukla, S.K., A review on thermal energy storage unit for solar thermal power plant application, International Conference on Technologies and Materials for Renewable Energy, Environment and Sustainability. Energy Procedia, 74, pp. 462-469, 2015.

https://doi.org/10.1016/j.egypro.2015.07.728

[13] Anzar, A. \& Shine, K., Transient thermal analysis of phase change material based heat sinks. International Journal of Research in Engineering and Technology, 2(11), pp. 703-714, 2013.

https://doi.org/10.15623/ijret.2013.0211107

[14] Hollmuller, P., Utilisation des échangeurs air/sol pour le chauffage et le rafraîchissement des bâtiments - Mesures in situ, modélisation analytique, simulation numérique et analyse systémique, Thesis presented to the Faculty of Science at the University of Geneva, ref. 3357, 25 June 2002.

[15] Hollmuller, P., Lachal, B. \& Zgraggen, J.M., A new ventilation and thermal storage technique for passive cooling of buildings: thermal phase-shifting, PLEA 23rd International conference on passive and low energy architecture, Geneva, Switzerland, 6-8 September 2006.

[16] Kumar, A. \& Shukla, S.K., A review on thermal energy storage unit for solar thermal power plant application, International Conference on Technologies and Materials for Renewable Energy, Environment and Sustainability, TMREES15, 2015. 